1 Title page

2 Title: The use of mutants and inhibitors to study sterol

3 biosynthesis in plants

4

5 Authors: Kjell De Vriese ${ }^{1,2}$, Jacob Pollier ${ }^{1,2,3}$, Alain Goossens ${ }^{1,2}$, Tom Beeckman ${ }^{1,2}$, Steffen

6 Vanneste ${ }^{1,2,4,^{*}}$

7 Affiliations:

8 1: Department of Plant Biotechnology and Bioinformatics, Ghent University, Technologiepark 71, 9052 Ghent, 9 Belgium

10 2: VIB Center for Plant Systems Biology, VIB, Technologiepark 71, 9052 Ghent, Belgium

11 3: VIB Metabolomics Core, Technologiepark 71, 9052 Ghent, Belgium

12 4: Lab of Plant Growth Analysis, Ghent University Global Campus, Songdomunhwa-Ro, 119, Yeonsu-gu, Incheon

1321985 , Republic of Korea

14

15 e-mails:

$16 \quad$ K.D.V: kjvri@psb.vib-ugent.be

17 J.P: japol@psb.vib-ugent.be

$18 \quad$ A.G. algoo@psb.vib-ugent.be

19 T.B. tobee@psb.vib-ugent.be

20 S.V. stnes@psb.vib-ugent.be

21

$22 \quad{ }^{*}$ Corresponding author

23 Tel: +32 93313844

24 Date of submission: sept $26^{\text {th }} 2019$

25 Number of Figures:3 in colour

26 Word count: 6126

27 
30

31

32

33

34

35

36

37

38

39

40

41

42

43

\title{
The use of mutants and inhibitors to study sterol biosynthesis in
} plants

\author{
Kjell De Vriese, Jacob Pollier, Alain Goossens, Tom Beeckman, Steffen Vanneste
}

\section{ABSTRACT}

Sterols are very well known for their important roles in membranes and signaling in eukaryotes. Plants stand out among eukaryotes by the large variety of sterols that they can produce, and employing them across a wide spectrum of physiological processes. Therefore, it is critical to understand the wiring of the biosynthetic pathways by which plants generate these distinct sterols, to allow manipulating them and dissect their precise physiological roles. Many enzymatic steps show a deep evolutionary conservation, while others are executed by completely different enzymes. Here, we review the complexity and variation of the biosynthetic routes of the most abundant phytosterols in the green lineage and how different enzymes in these pathways are conserved and diverged from humans,yeast and even bacteria. Based on their evolutionary conservation we discuss the use of human and yeast sterol biosynthesis inhibitors in plants, as an argument for the development of plant-tailored inhibitors of sterol biosynthesis. 
bioRxiv preprint doi: https://doi.org/10.1101/784272; this version posted September 26, 2019. The copyright holder for this preprint (which was not certified by peer review) is the author/funder, who has granted bioRxiv a license to display the preprint in perpetuity. It is made available under aCC-BY 4.0 International license.

51

52

53

54

55 


\section{Introduction}

Sterols are a class of triterpenoid lipids that consist of a hydrated phenanthrene group and a cyclopentane ring that have been a topic of great interest for researchers for many decades due to their essential physiological roles in eukaryotic organisms (Benveniste, 2004; Hartmann, 1998).

For instance, the sterol composition in membranes has a crucial impact on membrane fluidity and transmembrane export and import processes, and some sterols can even act as second messengers or signaling molecules during developmental and cellular signaling processes. The importance of sterols for eukaryotic organisms is even more apparent when looking from an evolutionary point of view, since the occurrence of sterol biosynthesis is thought to be a key evolutionary step in the advent of eukaryotic life (Galea and Brown, 2009).

Indeed, the ancient rise in atmospheric $\mathrm{O}_{2}$ levels to the current $21 \% \mathrm{O}_{2}$ not only drove the evolution of the earliest eukaryotic single-cell organisms, it also allowed for the occurrence of sterol biosynthesis pathways, which require $\mathrm{O}_{2}$ (Galea and Brown, 2009; Mouritsen, 2005). This is contrasted by the occurrence of hopanoids in prokaryotes, which are ring-structured molecules that look similar to sterols, but that do not require $\mathrm{O}_{2}$ for their biosynthesis and lack a $3 \beta$-hydroxyl group, but exert analogous functions in the membranes as cholesterol (Berry et al., 1993; Mangiarotti et al., 2019; Saenz et al., 2015). Intriguingly, the advent of sterol biosynthesis may also have acted as an early defense mechanism protecting against oxidative damage in these primitive eukaryotes, since sterols have been shown to function as a primitive cellular defense against $\mathrm{O}_{2}$ and reactive oxygen species (ROS) and are able to regulate cellular and organellar $\mathrm{O}_{2}$ entry (Galea and Brown, 2009). It is thus possible that primitive eukaryotes evolved sterols as an adaptive response to the rising atmospheric $\mathrm{O}_{2}$ levels, instead of just a consequence of it like previously assumed. Notably, some bacteria also produce sterols, presumably due to horizontal gene transfer (Bode et al., 2003; Rivas-Marin et al., 2019). 
While sterols occur in all eukaryotic organisms, the types and amounts of sterols varies

82

83

84

considerably between the different kingdoms. For instance, cholesterol is the major sterol produced in animals, whereas fungi mainly produce ergosterol. Plants, on the other hand, produce a wide variety of sterols (or phytosterols), with over 200 kinds known to date (Benveniste, 2004; Guo et al., 1995; Schaller, 2004). Within the phytosterols, campesterol, stigmasterol and $\beta$-sitosterol make up the predominant molecules of the sterol profile in plants (Benveniste, 2004; Hartmann, 1998): e.g. 64\% campesterol, 6\% stigmasterol and 11\% $\beta$ sitosterol in Arabidopsis (Benveniste, 2004; Schaeffer et al., 2001). These three phytosterols have either a methyl group (campesterol) or an ethyl group ( $\beta$-sitosterol and stigmasterol) on their C-24 position, and thus are also called 24-methylsterols and 24-ethylsterols, respectively (Schaller et al., 1998). The balance between 24-methylsterols and 24-ethylsterols differs between plant species and is highly regulated, since their ratio has an important effect on several cellular processes (Schaller, 2003). For instance, reproductive organs such as flowers and seedpods are negatively affected by moderate changes in the campesterol/ $\beta$-sitosterol ratio, while more severe changes in the campesterol/ $\beta$-sitosterol ratio have no significant effect on stem elongation (Schaller, 2003).

The main function of phytosterols is the regulation of the fluidity and permeability of membranes (Schaller, 2003). They achieve this by interacting with the saturated alkyl chains of the phospho- and sphingolipids that make up the membrane bilayers, thus limiting their mobility and permeability depending on the type and amount of sterols (Hartmann, 1998). While all of the phytosterols are able to regulate membrane fluidity and permeability, their efficiency in doing so varies (Hartmann, 1998; Schuler et al., 1990; Schuler et al., 1991). For instance, cholesterol has the largest stabilizing effect on membranes, followed by campesterol, $\beta$-sitosterol, and stigmasterol (Grunwald, 1971; Hodzic et al., 2008). Therefore, changes in the membrane sterol composition have an effect on the membrane permeability and function (Valitova et al., 2010). 
While phytosterols are mainly present in the PM, small amounts of them have also been found in membranes of the ER (Hartmann and Benveniste, 1987), mitochondria (Meance et al., 1976), vacuole (Yoshida and Uemura, 1986) and chloroplasts (Hartmann and Benveniste, 1987). Another function in membranes to which phytosterols contribute is the formation of so-called "lipid rafts". These lipid rafts are small, dynamic membrane domains rich in phytosterols and sphingolipids, in which certain enzymes and signaling complexes are gathered (Laloi et al., 2007; Malinsky et al., 2013; Simon-Plas et al., 2011; Simons and van Meer, 1988). Lipid rafts have been successfully identified and isolated in several plant species and detailed analyses of

114 their composition confirmed the presence of the main phytosterols campesterol, $\beta$-sitosterol and 115 stigmasterol, as well as other sterols, sterol glycosides and sphingolipids (Cacas et al., 2012; Mongrand et al., 2004; Simon-Plas et al., 2011). Consequently, the phytosterol content of

117 membranes indirectly affects enzyme activity, signal transduction, ion transport, and protein118 protein and protein-lipid interactions that take place in and over these membranes 119 (Grandmougin-Ferjani et al., 1997; Schaller, 2003).

This is evidenced by the wide range of severe phenotypes that were reported for 121 mutants defective in sterol biosynthesis. Phenotypes of such mutants include extreme dwarfism 122 and disturbances in embryogenesis, vascularization, fertility, cell differentiation and proliferation, 123 depending on the sterol biosynthesis step that is disturbed (Azpiroz et al., 1998; Catterou et al., 124 2001; Clouse, 2000; Guo et al., 1995; He et al., 2000; Piironen et al., 2000; Schaller, 2003). 125 Currently, the origin of these sterol mutant phenotypes is poorly understood. Some can be 126 explained by defects in auxin transport (Men et al., 2008; Pan et al., 2009; Titapiwatanakun et 127 al., 2009; Willemsen et al., 2003; Yang et al., 2013) or ethylene signaling (Souter et al., 2002), 128 whereas others derive from defects in brassinosteroid signaling as campesterol serves as a 129 biosynthetic precursor of the brassinosteroid brassinolide. Furthermore, there are indications 130 that phytosterols can act as signaling/regulatory molecules during plant growth and 
development (Fujioka and Sakurai, 1997; Guo et al., 1995; Lindsey et al., 2003; Vriet et al., 132 2013).

In conclusion, phytosterols not only are vital structural components of membranes, they also play key roles during plant growth and development. Therefore, the large variety of plant sterols allows plants to adapt to constantly changing environmental conditions.

\section{Conservation and divergence in the early sterol biosynthesis pathway}

The initial pathway from which all triterpenes (including phytosterols, lanosterol and cholesterol) are derived is called the mevalonate (MVA) pathway, which is largely conserved across eukaryotes and archaea (Buhaescu and Izzedine, 2007; Lombard and Moreira, 2011)

141 (Fig. 1). The end products of the MVA pathway are isopentenyl pyrophosphate (IPP) and 142 dimethylallyl pyrophosphate (DMAPP), which form the primary building blocks of all isoprenoids 143 (Goldstein and Brown, 1990).

The MVA pathway starts with the condensation of two acetyl-CoA molecules into acetoacetyl-CoA by acetoacetyl-CoA thiolase. An additional condensation in the next step 146 catalyzed by HMG-CoA synthase (HMGS) results in the formation of 3-hydroxy-3147 methylglutaryl-CoA (HMG-CoA). Subsequent reduction of HMG-CoA by HMG-CoA reductase 148 (HMGR) leads to the production of mevalonate. In contrast to humans, plants often have multiple HMGR isoforms in their genomes. For instance, the Arabidopsis genome contains two HMGR genes that encode for three HMGR isoforms, of which HMG1 is most abundantly expressed (Enjuto et al., 1994; Enjuto et al., 1995). Consistent with its biochemical role in the of squalene (Suzuki et al., 2004). 
In the last steps of the eukaryotic MVA pathway, MVA undergoes two phosphorylations at its $5-\mathrm{OH}$ position (catalyzed by mevalonate-5-kinase (MK) and phosphomevalonate kinase $(\mathrm{PMK})$ ), followed by a decarboxylation (catalyzed by mevalonate 5-diphosphate decarboxylase (MDD)), resulting in IPP. This IPP, together with its derivative DMAPP that is synthesized by IPP isomerase (IDI), form the starting molecules of the pathways leading to the production of a large variety of isoprenoids (Goldstein and Brown, 1990). Archaea use a modified MVA pathway in comparison to eukaryotes, in which the last three enzymes have been replaced by other enzymes (Boucher et al., 2004). via an alternative pathway: the methylerythritol phosphate (MEP) or non-mevalonate pathway (Banerjee and Sharkey, 2014; Chappell, 2002), which takes place in the plastids and is mostly used for the biosynthesis of various mono-, di- and tetraterpenoids (Laule et al., 2003; Zhao et al., 2013) (Fig. 1). The MEP pathway is the main pathway for IPP and DMAPP biosynthesis in bacteria, with some exceptions (Lombard and Moreira, 2011), and is obtained by plants during the endosymbiosis event with cyanobacteria that originated the plastids (Lange et al., 2000). used for the production of phytosterols, triterpenoids and sesquiterpenoids. Interestingly, many green algae species do not possess the MVA pathway and are solely reliant on the MEP 172 pathway for isoprenoid biosynthesis (Lohr et al., 2012). Notably, there are indications of 173 crosstalk between the cytosolic MVA and plastidial MEP pathways in plants (Mendoza174 Poudereux et al., 2015; Tansey and Shechter, 2001). Furthermore, it was recently shown that 175 plants express a functional homolog of the isopentenyl phosphate kinase (IPK) that was 176 originally identified in archaebacteria as part of their modified MVA pathway (Dellas and Noel, 177 2010; Henry et al., 2015). This enzyme catalyzes the phosphorylation of isopentenyl phosphate 178 (IP) and dimethylallyl phosphate (DMAP) into IPP and DMAPP, respectively, thus increasing 
their availability for terpenoid production (Henry et al., 2015; Henry et al., 2018). Interestingly, IPP can be dephosphorylated back to IP by a subset of Nudix superfamily hydrolases (Henry et al., 2018). Together, these findings illustrate the highly complex metabolic regulation of IPP and DMAPP levels for terpenoid biosynthesis in plants.

Subsequently, in the cytosol, farnesyl pyrophosphate (FPP) is formed by two sequential condensation reactions, in which two IPP molecules are added to DMAPP. These condensation reactions are catalyzed by farnesyl pyrophosphate synthase (FPPS) (Kulkarni et al., 2013). In the plastidial MEP pathway, on the other hand, FPP is synthesized in two steps, in which IPP and DMAPP are first converted to GPP by GPPS followed by the formation of FPP from GPP and IPP by a plastidial FPPS (Manzano et al., 2016). In the cytosol, FPP can either enter the sesquiterpene biosynthesis pathway, or be further converted to squalene, a C-30 molecule which is a condensation of two FPP units catalyzed by squalene synthase (SQS) (Tansey and Shechter, 2001). Squalene is produced via this pathway in both pro- and eukaryotes, where it is the universal precursor of hopanoids and steroids, respectively. In plants, animals and fungi, squalene is further converted to 2,3-oxidosqualene by squalene epoxidase (SQE; see further) (Thimmappa et al., 2014). 


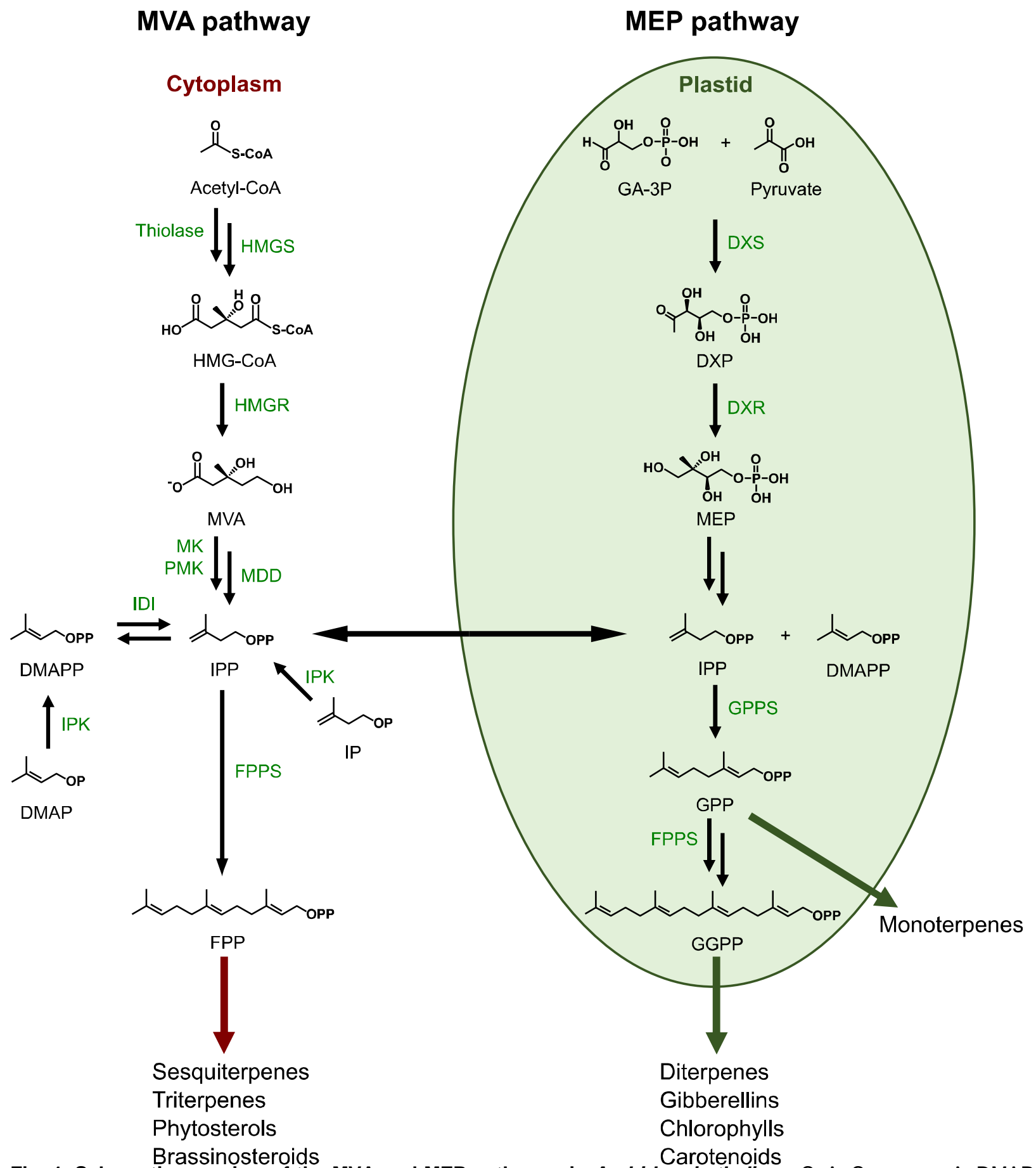

Fig. 1. Schematic overview of the MVA and MEP pathways in Arabidopsis thaliana. CoA, Coenzyme A; DMAP, dimethylallyl phosphate; DMAPP, dimethylallyl pyrophosphate; DXP, 1-deoxy-D-xylulose 5-phosphate; DXR, DXP reductoisomerase; DXS, DXP synthase; FPP, farnesyl pyrophosphate; FPPS, farnesyl pyrophosphate synthase; GA3P, glyceraldehyde 3-phosphate; GGPP, geranylgeranyl pyrophosphate; GPP, geranyl pyrophosphate; GPPS, geranyl pyrophosphate synthase; HMG, 3-Hydroxy-3-methylglutaryl; HMGR, HMG-CoA reductase; HMGS, HMGCoA synthase; IDI, IPP isomerase; IPK, isopentenyl phosphate kinase; IP, isopentenyl phosphate; IPP, isopentenyl pyrophosphate; MDD, mevalonate 5-diphosphate decarboxylase; MEP, methylerythritol phosphate; MK, mevalonate5-kinase; MVA, mevalonate; PMK, phosphomevalonate kinase. 


\section{Early Phytosterol biosynthesis - 2,3-oxidosqualene as a precursor for}

206

207

208

209

210

211

212

213

214

215

216

217

218

219

220

221

222

223

224

225

226

227

228

phytosterols

As mentioned before, the biosynthesis of sterols in eukaryotes begins with the epoxidation of squalene into 2,3-oxidosqualene by SQUALENE EPOXIDASEs (SQE) (Thimmappa et al., 2014). Of three functional SQEs in Arabidopsis that can rescue SQE deficient yeast (Laranjeira et al., 2015; Rasbery et al., 2007), SQE1 seems to play the most predominant function, as a single mutant displays pleiotropic phenotypes in the root and shoot (Pose et al., 2009; Rasbery et al., 2007). However, these phenotypes were not due to the reduced sterol content of the mutant, but rather due to its hyperaccumulation of squalene (Doblas et al., 2013). Moreover, the sqe1 phenotypes could be explained by misregulation of ROS production (Pose et al., 2009), unlike later sterol biosynthetic mutants that display misregulated ethylene production and auxin transport (See further) (Souter et al., 2002; Souter et al., 2004). This observation gives further credibility to the hypothesis that sterol biosynthesis may have evolved as an adaptation to oxidative stress (Galea and Brown, 2009). Furthermore, these data provide evidence for a primordial role for a conserved oxidosqualene biosynthesis pathway acting as the earliest section of the phytosterol biosynthesis pathway. However, the absence of completely predictable reductions in the total phytosterol levels upon interference with enzymes involved in oxidosqualene biosynthesis indicates an important gap in our understanding of how early phytosterol biosynthesis is regulated. Indeed, recently, an alternative SQE has been identified in the diatom Phaeodactylum tricornutum, that belongs to the fatty acid hydroxylase superfamily instead of to the flavoprotein monooxygenases like the conventional SQEs (Pollier et al., 2019). This suggests that different enzymatic reactions in plant phytosterol biosynthesis can be mediated by a wider palette of enzymes than would be expected based on sequence homology to yeast and human sterol biosynthetic genes. 
Depending on the plant species, there are multiple cyclization pathways that convert 2,3oxidosqualene into different cyclic triterpene derivatives, based on the oxidosqualene cyclases (OSCs) that are present. These OSCs evolved from bacterial squalene/hopane synthases, and include cycloartenol synthase (CAS), lanosterol synthase (LAS), thalianol synthase (THAS) and ß-amyrin synthase (bAS) (Sawai et al., 2006; Thimmappa et al., 2014). The most prominent of

234 these pathways starts with the cyclization of 2,3-oxidosqualene into cycloartenol, which is 235 catalyzed by the enzyme cycloartenol synthase 1 (CAS1) in Arabidopsis (Gas-Pascual et al., 236 2014; Rees et al., 1969; Thimmappa et al., 2014). This pathway mainly produces the three major phytosterols as end-products, namely campesterol, $\beta$-sitosterol and stigmasterol, via a complex series of enzyme-catalyzed conversions. Interestingly, the bacterium Stigmatella aurantiaca also produces cycloartenol via a CAS enzyme that is similar to that of plants (Bode et al., 2003), and a squalene monooxygenase and an OSC were found to be essential for lanosterol biosynthesis in the bacterium Gemmata obscuriglobus (Rivas-Marin et al., 2019). group at the C-24 position by C-24 sterol methyltransferase 1 (SMT1), which is a key regulatory step of phytosterol biosynthesis (Neelakandan et al., 2009; Shi et al., 1996). In the next step, removal of a methyl group from the C-4 position of 24-methylenecycloartenol leads to in 246 cycloeucalenol. In Arabidopsis, this step is catalyzed by three members of the sterol-4a-methyl 247 oxidase 1 (SMO1) enzyme family (Darnet and Rahier, 2004). The opening of the cyclopropane 248 ring of cycloeucalenol by cycloeucalenol cycloisomerase (CPI1) subsequently leads to the 249 production of obtusifoliol (Benveniste, 2002). Obtusifoliol then undergoes demethylation of its C25014 position, which results in the formation of $4 \alpha$-methyl-5a-ergosta-8,14,24(28)-trien-3 $\beta$-ol 251 (Rahier and Taton, 1986). This reaction is catalyzed by obtusifoliol 14a-demethylase (CYP51G1 252 in Arabidopsis), a cytochrome P450 enzyme. Next, 4a-methyl-5a-ergosta-8,14,24(28)-trien-3ß253 ol is converted to $4 a$-methylfecosterol by the sterol C-14 reductase FACKEL (FK). In the 
254 following step, the C-7 double bond of $4 a-$ methylfecosterol undergoes a reduction catalyzed by 255 the C-8,7 sterol isomerase HYDRA1 (HYD1) (Souter et al., 2002), which leads to the formation 256 of 24-methylenelophenol. corresponding mutants often display strong phenotypes, including cpi, smt1, cyp51, hyd1 and fk. The cpi mutant is characterized by increased levels of cycloeucalenol and its derivatives, and has severe defects in its growth and development (Men et al., 2008). The smt1, hyd1 and fk mutants have reduced phytosterol and BR levels, and are severely impaired in embryogenesis, cell polarity, root growth, gravitropism and vascular development (Diener et al., 2000; Schrick et al., 2000; Souter et al., 2002; Topping et al., 1997; Willemsen et al., 2003). The abnormal vascular development phenotype of the hyd1 and $f k$ mutants could be partially rescued by crossing these mutants with auxin-resistant mutants, indicating that the hyd1 and fk mutants may have disturbed auxin signaling or transport (Souter et al., 2002). Similarly, the abnormal root phenotype in hyd1 and $f k$ could be rescued by crossing these mutants with a dominant ethylene-resistant mutant, suggesting they also have disturbed ethylene signaling (Souter et al., 2002). Recently, tissue-specific complementation of the hyd1 mutant suggests that many of its

270 phenotypes can be explained by defective patterning of PIN auxin transporters, and associated 271 defects in auxin transport (Diener et al., 2000). Interestingly, the smt1 mutant is hypersensitive 272 to $\mathrm{Ca}^{2+}$ ions, since lowering the $\mathrm{Ca}^{2+}$ concentration in the growth medium of this mutant resulted 273 in improved root growth, probably due to alterations in membrane permeability (Diener et al., 274 2000). 
bioRxiv preprint doi: https://doi.org/10.1101/784272; this version posted September 26, 2019. The copyright holder for this preprint (which was not certified by peer review) is the author/funder, who has granted bioRxiv a license to display the preprint in perpetuity. It is made available under aCC-BY 4.0 International license.

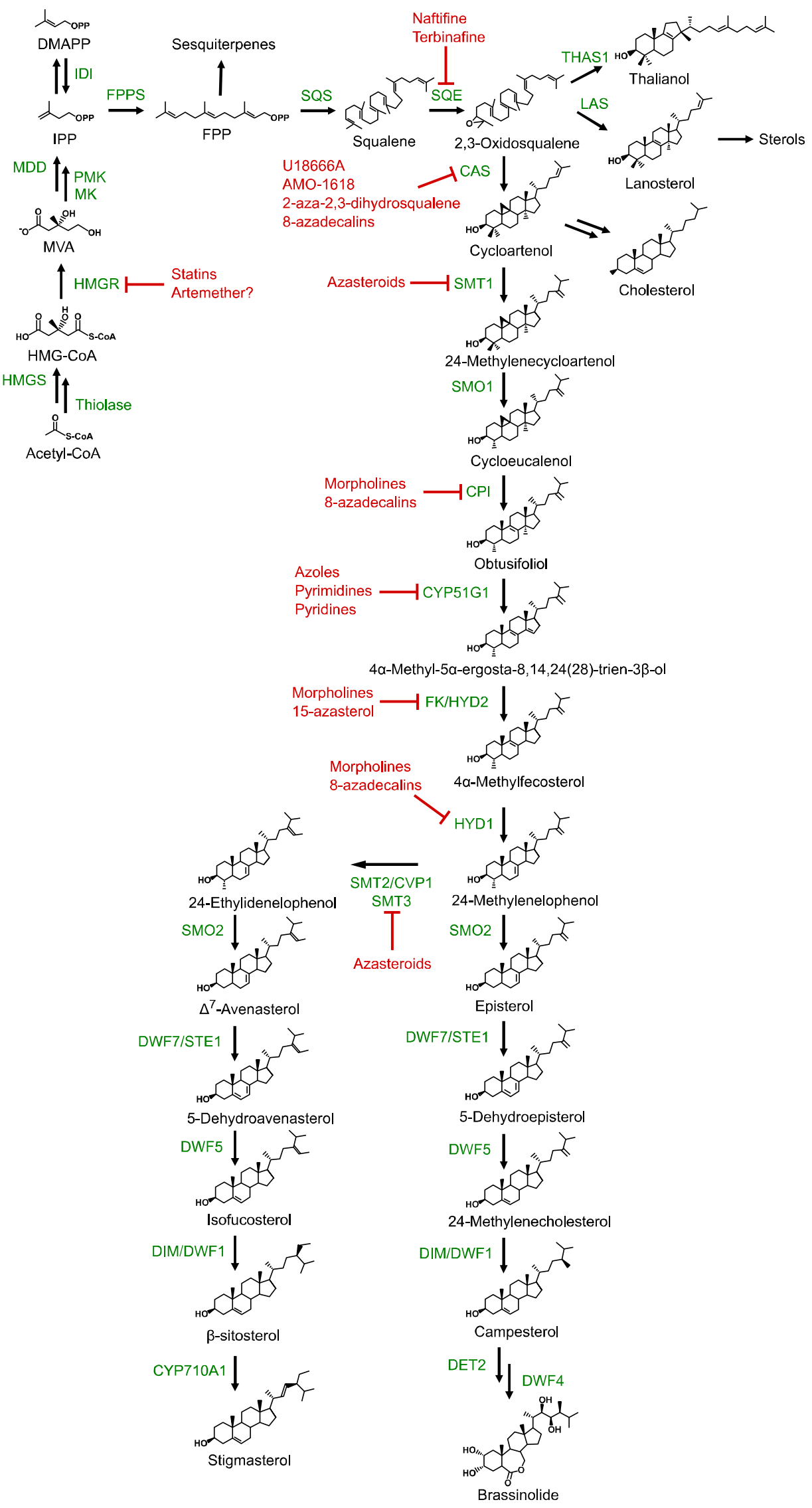


Fig. 2. Schematic overview of the main sterol biosynthesis pathway in Arabidopsis thaliana and putative target sites of inhibitors. CAS, cycloartenol synthase; CoA, Coenzyme A; CPI, cycloeucalenol cycloisomerase; CVP1, cotyledon vascular pattern 1; CYP51G1, cytochrome P450 51G1; CYP710A1, cytochrome P450 710A1; DET2, DEETIOLATED2; DIM, DIMINUTO; DMAPP, dimethylallyl pyrophosphate; DWF1/5/7, DWARF1/5/7; FK, FACKEL; FPP, farnesyl pyrophosphate; FPPS, farnesyl pyrophosphate synthase; HMG, 3-Hydroxy-3-methylglutaryl; HMGR, HMG-CoA reductase; HMGS, HMG-CoA synthase; HYD, HYDRA; IDI, IPP isomerase; IPP, isopentenyl pyrophosphate; LAS, lanosterol synthase; MDD, mevalonate 5-diphosphate decarboxylase; MK, mevalonate-5kinase; MVA, mevalonate; PMK, phosphomevalonate kinase; SMO, sterol-4a-methyl oxidase; SMT1/2/3, C-24 sterol methyltransferase 1/2/3; SQE, squalene epoxidase; SQS, squalene synthase; STE1, STEROL1; THAS1, thalianol synthase.

\section{Phytosterol biosynthesis - parallel branches for stigmasterol and campesterol}

From 24-methylenelophenol onwards, the pathway bifurcates via two separate branches, eventually resulting in either 24-ethylsterols ( $\beta$-sitosterol and stigmasterol) or 24methylsterols (campesterol) as end-products, respectively. Campesterol can subsequently be used as a precursor for brassinosteroid biosynthesis.

The 24-ethylsterol branch pathway begins with a second methylation of the C-24 position of 24-methylenelophenol by the enzymes C-24 sterol methyltransferase 2/cotyledon vascular pattern 1 (SMT2/CVP1) and C-24 sterol methyltransferase 3 (SMT3), which results in 24-ethylidenelophenol (Bouvier-Nave et al., 1998; Carland et al., 2010). Like with SMT1, the reaction catalyzed by SMT2/CVP1 is an important regulatory step in sterol biosynthesis, since it determines the ratio of 24-methyl- and 24-ethylsterols, which affects several developmental processes in plants (Bouvier-Nave et al., 1997; Carland et al., 2002; Schaeffer et al., 2001). Interestingly, it is thought that SMT2/CVP1 is also able to catalyze the primary C-24 methylation catalyzed by SMT1, albeit to a lesser extend (Schaeffer et al., 2001). A following double demethylation of 24-ethylidenelophenol by sterol-4a-methyl oxidase 2 (SMO2) results in the formation of $\Delta^{7}$-avenasterol (Darnet and Rahier, 2004), which is subsequently converted to 5dehydroavenasterol by the $\Delta^{7}$-sterol-C5-desaturase DWARF7/STEROL1 (DWF7/STE1) (Choe et al., 1999b; Gachotte et al., 1996). Next, the sterol $\Delta^{7}$-reductase DWARF5 (DWF5) converts 
this 5-dehydroavenasterol into isofucosterol (Choe et al., 2000). Finally, a C-24 reduction of isofucosterol by the $\Delta^{24}$-sterol- $\Delta^{24}$-reductase DIMINUTO/DWARF1 (DIM/DWF1) leads to the generation of $\beta$-sitosterol (Choe et al., 1999a), which can then undergo a further C-22 desaturation by the C-22 sterol desaturase CYP710A1, resulting in the end-product of this pathway: stigmasterol (Morikawa et al., 2006). However, not many details are known about this desaturation reaction in higher plants. Interestingly, in Arabidopsis, a second CYP710 enzyme (CYP710A2) is also able to produce stigmasterol from $\beta$-sitosterol, and can also produce brassicasterol from 24-epi-campesterol (Benveniste, 2002; Morikawa et al., 2006). leads to the production of campesterol is similar to the first one and mostly uses the same and Rahier, 2004). The rest of the pathway consists of the same steps as the first branched pathway. First STE1 causes a desaturation of the C-5 position of episterol, which results in 5322 dehydroepisterol. This is followed by a reduction of its C-7 position by DWF5, leading to 24323 methylenecholesterol (Choe et al., 2000). Finally, a reduction of the C-24 double bond of 24324 methylenecholesterol by DIM/DWF1 yields the end-product of this pathway: campesterol. 325 Besides its function as a structural phytosterol in membranes, campesterol also acts as a 326 precursor for the brassinosteroid biosynthesis pathway (Choe et al., 1999a; Clouse, 2011). For 327 details about brassinosteroid biosynthesis, we refer to dedicated reviews (Choe et al., 1999a; 328 Clouse, 2011).

The smt2/cvp1 mutant has increased campesterol levels and reduced $\beta$-sitosterol levels, 330 and is characterized by moderate developmental defects, such as disturbed venation patterns in 331 its cotyledons, serrated floral organs and a reduced stature (Carland et al., 2010; Carland et al., 
2002). Unlike the early sterol biosynthesis mutants $s m t 1$, hyd1 and $f k$, more downstream sterol biosynthesis mutants such as smt2/cvp1, dim/dwf1, dwf5 and dwf7/ste1 show no defects in embryogenesis. The smt2/cvp1 mutant is smaller than the wild type, but it doesn't demonstrate extreme dwarfism (Carland et al., 2002). Although dim/dwf1, dwf5 and dwf7/ste1 affect successive steps in the conversion of episterol to campesterol, and $\Delta^{7}$-avenasterol to $\beta$ sitosterol (Choe et al., 1999a; Choe et al., 1999b; Clouse, 2002), the phenotypes of these mutants resemble those of brassinosteroid-deficient mutants, reflecting the importance of campesterol as a precursor of the most biologically active brassinosteroid, brassinolide. However, while these mutants are significantly smaller than wild-type plants, they don't display the extreme dwarfism that is typical of BR biosynthesis mutants. Furthermore, the sterol profile of these mutants is vastly disturbed, with $d w f 7 / s t e 1$ being almost completely devoid of campesterol (Choe et al., 1999b; Choe et al., 2000). These macroscopic phenotypes can be partially rescued by external application of BRs (Choe et al., 1999a; Choe et al., 1999b; Choe et al., 2000; Klahre et al., 1998; Schaller, 2003), demonstrating that they are largely caused by an impairment in downstream BR synthesis, rather than a direct effect of campesterol deficiency. However, since DIM/DWF1, DWF5 and DWF7/STE1 also catalyze the conversion steps of $\Delta^{7}$ avenasterol to $\beta$-sitosterol (Fig. 2), their respective mutants are not only deficient in campesterol, but also in $\beta$-sitosterol and stigmasterol, suggesting that the resulting defects in membrane integrity are at least partially responsible for the observed phenotypes of these mutants. This is presumably the case for the observed fertility defects, since BR application does not restore fertility in these mutants, suggesting that phytosterols play an important role during the plant reproduction that is independent from BRs (Schaller, 2004).

Furthermore, unlike $\operatorname{dim} / d w f 1, d w f 5$ and $d w f 7 / s t e 1$, the phenotypes of smt2/cvp1 and the early sterol biosynthesis mutants smt1, cpi, fk and hyd1 cannot be rescued by BR treatment (Carland et al., 2002; Diener et al., 2000; Schrick et al., 2000). Since these phenotypes are 
independent from the downstream BR pathway, it is possible that early synthesized sterols (sterol biosynthesis intermediates) can act as signaling molecules themselves, similar to what has been shown for cholesterol in animals (Edwards and Ericsson, 1999; Farese and Herz, 1998; Vriet et al., 2013). For example, accumulation of the sterol biosynthesis intermediate 4carboxy-4-methyl-24-methylenecycloartanol (CMMC), which accumulated in a mutant defective in tethering the sterol C4-demethylation complex, interferes with auxin transport (Edwards and

363 Ericsson, 1999; Farese and Herz, 1998; Vriet et al., 2013). Also of note is that the sterol biosynthesis pathways are relatively conserved between Eukaryotes, with diatoms and yeast using mostly similar or identical enzymes as the higher plants, albeit sometimes in a different order, which explains the difference in end products obtained (e.g. ergosterol in yeast and brassicasterol/campesterol in diatoms) (Fabris et al., 2014). Overall, these mutants of early and late steps of the sterol biosynthesis pathway have been excellent tools in aiding our understanding of plant sterol biosynthesis and the role of sterols in plant growth and development.

\section{Cholesterol biosynthesis in plants}

The major sterols in plants are $\beta$-sitosterol, campesterol and stigmasterol, but many

374 plants also produce cholesterol to some degree (Behrman and Gopalan, 2005). While the 375 cholesterol levels in plants are usually low (100 - 1000 times lower compared to animals), 376 cholesterol makes up a significant portion of the sterol content in some plant species (e.g. more 377 than $10 \%$ in Solanaceae) (Sonawane et al., 2016). Furthermore, it has been shown to serve 378 several functions in various plant species, including as membrane component, leaf surface lipid, 379 and precursor for several plant metabolites such as steroidal glycoalkaloids (SGAs) and 380 phytoecdysteroids (Cardenas et al., 2015; Dinan, 2001; Japelt and Jakobsen, 2013; Milner et 381 al., 2011). 

data, as well as a combination of functional assays (Sonawane et al., 2016). These data demonstrated the involvement of 12 enzymes in the tomato cholesterol biosynthesis pathway, of which several also function in the phytosterol biosynthesis pathway to catalyze highly related enzymatic conversions. Furthermore, the other enzymes that are specific for the cholesterol biosynthesis pathway seem to have evolved through gene duplication and divergence from 391 phytosterol biosynthetic enzymes (Sonawane et al., 2016). Unlike animals, cholesterol biosynthesis in plants does not seem to start from 2,3-oxidosqualene cyclization into lanosterol by LAS (Sonawane et al., 2016). Instead, the OSC involved is CAS, after which cycloartenol is not only used for phytosterol biosynthesis, but also cholesterol biosynthesis (Fig. 2). Indeed, in tomato and potato plants it was shown that sterol side chain reductase 2 (SSR2) is a key enzyme in cholesterol biosynthesis that catalyzes the conversion of cycloartenol into cycloartanol, the first committed step in cholesterol biosynthesis (Sonawane et al., 2016). However, while LAS probably doesn't contribute significantly to cholesterol biosynthesis, LAS genes were identified in several plant species, including Arabidopsis (Kolesnikova et al., 2006; Sawai et al., 2006; Suzuki et al., 2006). Furthermore, it was shown that LAS1 overexpression in Arabidopsis significantly increases the phytosterol levels while las1 knockout mutants do not 402 have phytosterols derived from lanosterol, indicating that there exists an alternative phytosterol 403 biosynthesis pathway that is dependent on LAS (Ohyama et al., 2009). The existence of 404 alternative pathways contributing to phytosterol biosynthesis could explain why phytosterol 405 levels in cas1 mutants remain unchanged, despite a strong defect in cycloartenol synthase 406 activity as indicated by the accumulation of 2,3-oxidosqualene (Babiychuk et al., 2008). 
411 (Fig. 2, Fig. 3). Indeed, sterol biosynthesis inhibitors have proven to be effective tools to probe

412 and investigate sterol biosynthesis pathways across the different kingdoms. Many of the

413 currently used sterol biosynthesis inhibitors have seen commercial use as fungicides and

414 antimycotic drugs, and some can even be used to regulate plant growth (Lenton, 1987; Leroux

415 et al., 2008). Since the sterol biosynthesis pathways of plants, animals and yeast share many

416 similar conversion steps that are catalyzed by semi-conserved enzymes, several of the most

417 used sterol biosynthesis inhibitors function across kingdoms (Ator et al., 1992). Nevertheless,

418 there still exist clear differences in the sterol biosynthesis pathways between the kingdoms,

419 leading to different sensitivities and specificities of sterol biosynthesis inhibitors (Nes, 2011).

420 The following paragraphs will go into more detail about some of the most active and most used

421 sterol biosynthesis inhibitors in plants, and their presumed targets. The compounds discussed

422 and their presumed targets in Arabidopsis are indicated in Fig. 2. The numbers in brackets

423 behind the discussed compounds correlate to their numbers in Fig. 3.

425 (Istvan and Deisenhofer, 2001). Because HMGR is a rate-limiting enzyme in MVA biosynthesis, 426 statin-based medication is widely used to lower cholesterol levels (reviewed in (Davies et al., 427 2016). In several plant species, statins, such as lovastatin (1) (or mevilonin) and mevastatin (2) 428 (or compactin), reduce root growth and sterol biosynthesis (Bach and Lichtenthaler, 1982, 1987;

429 Kim et al., 2014; Soto et al., 2011), demonstrating that statins can also be used as HMGR 430 inhibitors in plant sterol research. 
Two allylamine fungicides, namely naftifine (3) and terbinafine (4), are potent noncompetitive SQE inhibitors in fungi (Birnbaum, 1990; Ryder, 1991; Nowosielski et al., 2011).

433 Docking analyses on modelled SQE suggest that terbinafine binding causes a conformational 434 change that blocks one mode of substrate binding, while changing the geometry of another. 435 (Nowosielski et al., 2011). Although plant SQEs can complement yeast SQE deficient mutants 436 (Rasbery et al., 2007), they are not highly sensitive to these inhibitors (Yates et al., 1991, 1992; 437 Wentzinger et al., 2002). This is not surprising as single amino acid substitutions in yeast SQE 438 are sufficient to confer terbinafine resistance (Leber et al., 2003). Yet, the sqe1-5 mutant is 439 hypersensitive to terbinafine (Pose et al., 2009). On the other hand, some organisms such as the diatom $P$. tricornutum are completely insensitive to terbinafine as they use alternative SQES 441 (Fabris et al., 2014; Pollier et al., 2019). inhibitors of rat SQS, with apparent subnanomolar Ki values (Baxter et al., 1992; Bergstrom et al., 1993). Also in plants, squalestatins are highly potent, as they inhibit SQS in BY-2 cell suspensions with an $\mathrm{IC}_{50}$ value of $5.5 \mathrm{nM}$, possibly via an irreversible inhibition mechanism 446 (Hartmann et al., 2000; Wentzinger et al., 2002). Exogenous application of squalestatin 447 activates transcriptional responses also seen in lovastatin-treated plants and impairs the plants 448 fertility (Suzuki et al., 2004). The Arabidopsis genome encodes only a single functional SQS 449 (SQS1; Busquets et al., 2008), but has not yet been subjected to mutant analysis. degrees by mimicking the carbocationic intermediates formed during the cyclization of 2,3452 oxidosqualene. Some examples of OSC inhibitors that have been successfully utilized in plants 453 are 2-aza-2,3-dihydrosqualene (5) (Duriatti et al., 1985; Cattel et al., 1986), U18666A (6) 454 (Duriatti et al., 1985; Cattel et al., 1986) and AMO-1618 (7) (Douglas and Paleg, 1978, 1978, 455 1981). Another class of OSC inhibitors are the 8-azadecalins, such as 4,4,10ß-trimethyl-trans- 
decal-3ß-ol (TMD) (8) and its derivatives (Ruhl et al., 1989; Raveendranath et al., 1990; Hoshino et al., 1995). However, the 8-azadecalins also inhibit other enzymes besides OSCs (such as cyclopropyl sterol isomerase, C-14 sterol reductase and C-8,7 sterol isomerase), thus potentially leading to off-target effects.

In Arabidopsis, the C-24 sterol methyltransferase SMT1 catalyzes the transfer of a methyl group from S-adenosyl-L-methionine to cycloartenol (Benveniste, 1986; Bouvier-Nave et al., 1998; Diener et al., 2000), leading to the formation of $\Delta^{5}$ C-24 alkyl sterols. Since SMT1 only occurs in plants and fungi, and not in animals, it is an interesting target for studying phytosterol biosynthesis. SMT2/CVP1 and SMT3 are mainly responsible for a second methyl addition, thus resulting in an ethyl side-chain addition on the C-24 (Schaeffer et al., 2001; Carland et al., 2010). Therefore, the regulation of the SMT enzymes determines the sterol composition in plants. Many compounds have been designed over the years to act as SMT inhibitors (Nes, 2000). These inhibitors can be broadly classified in three groups: 1) substrate analogues that act as inactivators of the enzyme, 2) substrate analogues that resemble high-energy intermediates, and 3) product analogues. While these compounds are generally designed in fungal systems, some of them have been shown to inhibit SMT1 and SMT2/CVP1 in plants as well, including the azasteroid inhibitors 25-azacycloartenol (9) (Rahier et al., 1980; Schmitt et al., 1981; Rahier et al., 1986; Mangla and Nes, 2000), 25-azalanosterol (10) (Rahier et al., 1984) and 24-epiiminolanosterol (11) (Tal and Nes, 1987), which are carbocationic transition state analogues of the substrates of these enzymes (Rahier et al., 1984).

The 14a-methylsterol demethylase enzyme in plants (obtusifoliol 14a-demethylase) catalyzes the demethylation of obtusifoliol (Lepesheva and Waterman, 2007). This enzyme is a cytochrome P450 dependent monooxygenase (CYP51G1 in Arabidopsis) (Benveniste, 1986; Lepesheva and Waterman, 2007). In fungi and animals, the best studied and most widely used inhibitors of P450s are the azoles, which are a popular type of antifungal compounds that are 
used for both agricultural and medical purposes (Becher and Wirsel, 2012). Two subclasses of

482 the azoles are the imidazoles, such as clotrimazole (12), oxiconazole (13), ketoconazole (14),

483 imazalil (enilconazole) (15) and prochloraz (16), and the triazoles, such as triadimenol (17),

484 voriconazole (18) and fluconazole (19). They are nitrogen-containing heterocyclic compounds

485 that form an effective class of fungicides by non-competitively binding to the ferric ion of the

486 heme group of fungal CYP51, thus preventing it from binding its substrate (Rogerson et al.,

487 1977; Warrilow et al., 2013). Despite being primarily used as fungicides, several azole

488 compounds also have an effect on plants to a varying degree, where they generally cause

489 growth inhibition, which may be due to interference with downstream BR biosynthesis

490 (Scheinpflug and Kuck, 1987; Vanden Bossche et al., 1987; Rozhon et al., 2013; Fabris et al.,

491 2014). However, while nanomolar concentrations of azoles are usually sufficient to inhibit

492 ergosterol biosynthesis in fungi, micromolar concentrations or higher are often needed to obtain

493 a similar inhibitory effect on phytosterol biosynthesis in plants and diatoms (Vanden Bossche et

494 al., 1987; Fabris et al., 2014). The cytochrome P450s are a superfamily of enzymes (Xu et al.,

495 2015), that are often sensitive to imidazoles (Murray, 1999). Of note is that azoles can be found

496 or even designed that display a certain degree of preference towards specific cytochrome P450

497 enzymes. Well-known examples in plants are uniconazole as an inhibitor of CYP707As that are

498 involved in abscisic acid catabolism (Saito et al., 2006), and brassinazole as an inhibitor of

499 CYP90B1 that is involved in brassinosteroid biosynthesis (Asami et al., 2000). Importantly, both

500 uniconazole and brassinazole can inhibit CYP90B1 activities, suggesting that one should be

501 wary of off-target side effects when using these inhibitors, especially when using them at high

502 concentrations. Recently, analysis of crystals of CYP90B1 in complex with uniconazole and

503 brassinazole demonstrated important differences in binding conformation (Fujiyama et al., 2019)

504 which highlighted the importance of using crystal structures of plant CYPs to guide the design of 505 new, more-specific inhibitors. 
Besides the azoles, also pyrimidine-type fungicides, such as fenarimol (20), nuarimol

507 (21) and triarimol (22), and pyridine-type fungicides are thought to affect the CYP51 ortholog 508 and other cytochrome P450 enzymes, such as CYP710A1 in plants (Shive and Sisler, 1976;

509 Schmitt and Benveniste, 1979; Buchenauer and Rohner, 1981; Burden et al., 1987; Scheinpflug

510 and Kuck, 1987; Mercer et al., 1989; Leroux et al., 2008; Oh et al., 2015). Overall, these

511 compounds all cause strong reductions in root- and shoot growth with varying potency, and are

512 phytotoxic at high concentrations due to a severe reduction in phytosterols and an accumulation

513 of 14a-methylsterols (Burden et al., 1987; Lurssen, 1987). shared targets for molecular inhibition. An important class of inhibitors that target these Mercer, 1987; Mercer et al., 1989; Marcireau et al., 1990). These compounds exert their

520 fungitoxicity by inhibiting C-8,7 sterol isomerase (nM concentrations) and/or C-14 sterol 521 reductase ( $\mu \mathrm{M}$ concentration) in fungi and yeast, with different morpholines having different 522 specificities (Kerkenaar et al., 1981; Baloch et al., 1984; Baloch and Mercer, 1987; Kerkenaar, 523 1987; Marcireau et al., 1990). For instance, while fenpropimorph can effectively inhibit both the 524 C-8,7 sterol isomerase and C-14 sterol reductase in fungi, tridemorph primarily inhibits the C-8,7 525 sterol isomerase (Baloch et al., 1984; Kerkenaar, 1987). However, morpholines also function in 526 plants, albeit less potently and less specifically, where they have been shown to inhibit HYD1 527 (the plant C-8,7 sterol isomerase) (Rahier et al., 1986; Taton et al., 1987), FK (the plant C-14 528 sterol reductase) (Mercer et al., 1989; Taton et al., 1989; He et al., 2003) and CPI (Taton et al., 529 1987) to a varying degree. Similarly, fenpropimorph treatment caused alterations in the sterol 530 content of the diatom $P$. tricornutum that could be explained by inhibition of multiple enzymes 
531 involved in its sterol biosynthesis pathway (Fabris et al., 2014). While fenpropimorph is the most

532 active and commonly used morpholine in plants, it requires relatively high concentrations to

533 function $(30-100 \mu \mathrm{M})$, is unstable and relatively expensive. Plants treated with morpholines

534 have a disturbed sterol profile and growth impairments, similar to mutants defective in the

535 targeted enzymes (Bladocha and Benveniste, 1983; Burden et al., 1987; He et al., 2003).

536 However, while the morpholine compounds disturb the normal sterol profile of plants, they are

537 generally not phytotoxic (Bladocha and Benveniste, 1983; Taton et al., 1987, 1987).

538 Interestingly, in plants, 8-azadecalins such as N-benzyl-8-aza-4a,10-dimethyl-trans-decal-3ß-ol

539 (27) and N-(1,5,9-trimethyldecyl)-4a,10-dimethyl-8-aza-trans-decal-3ß-ol (TMDAD) (28) have

540 been shown to be more potent inhibitors of HYD1 and CPI than the morpholines (Rahier et al.,

541 1985; Taton et al., 1987). A strong, more specific inhibitor of C-14 sterol reductases is the

542 antifungal agent 15-aza-24-methylene-D-homocholesta-8,14-dien-3ß-ol (15-azasterol) (29),

543 which has been used to inhibit FK in several plant species, including Arabidopsis (Schrick et al.,

544 2002) and bramble cells (Schmitt et al., 1980).

While most of the abovementioned sterol biosynthesis inhibitors have been used to

546 inhibit plant growth and study plant and diatom sterol biosynthesis to some degree, it is clear

547 that many of these compounds originate as antifungal compounds for which the effect in plants

548 is often not completely understood. Indeed, much of the underlying mechanisms of these

549 inhibitors in plants and diatoms are still not completely clear and are often presumed based on

550 their function in fungi and/or animals. It should also be noted that only limited recent data is

551 available for most of these inhibitors in plants, as evidenced by the relatively old sources

552 referenced in the last paragraphs. This further supports the notion that the current knowledge

553 and toolset of sterol biosynthesis inhibitors in plants is lacking. The identification of more active

554 compounds that selectively target specific enzymes in the plant sterol biosynthesis pathway 
bioRxiv preprint doi: https://doi.org/10.1101/784272; this version posted September 26, 2019. The copyright holder for this preprint (which was not certified by peer review) is the author/funder, who has granted bioRxiv a license to display the preprint in perpetuity. It is made available under aCC-BY 4.0 International license.

555 through a systematic approach, informed by crystal structures, would therefore be highly 556 welcomed to study sterol biosynthesis in the green lineage. 

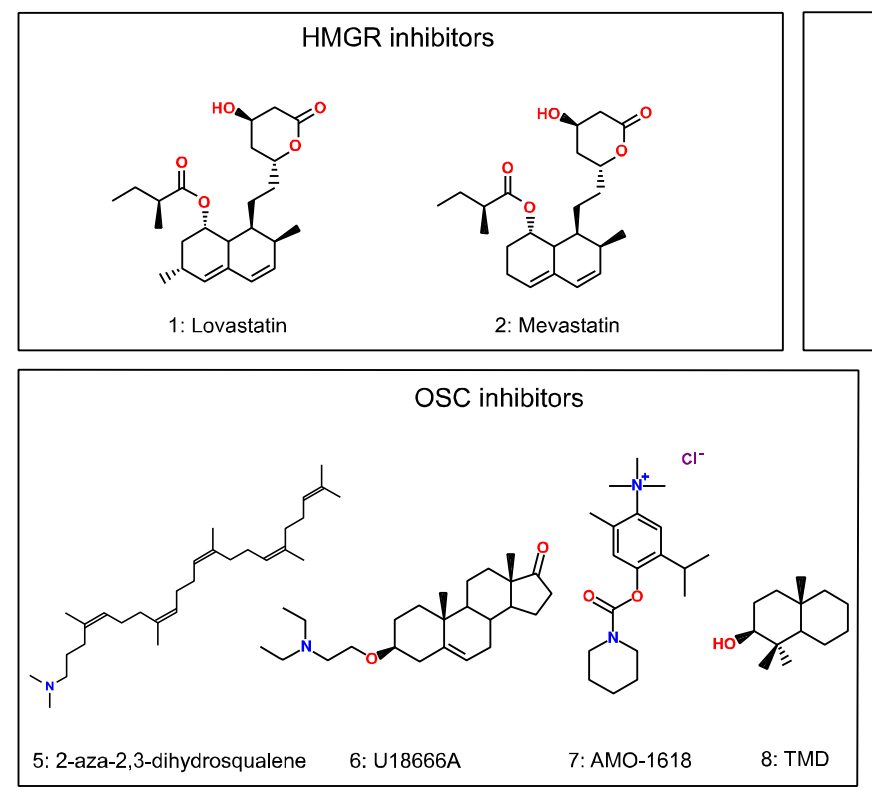

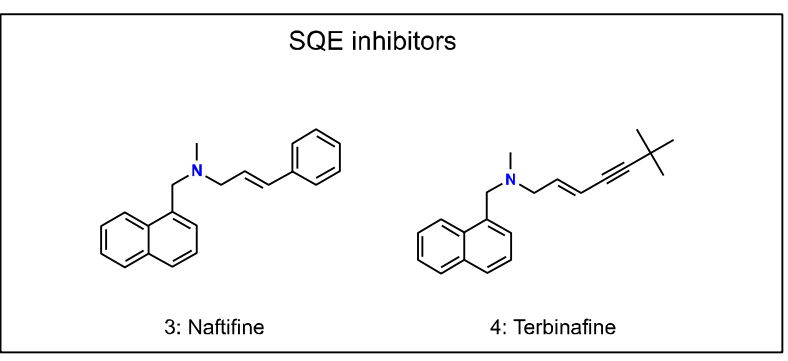

SMT inhibitors

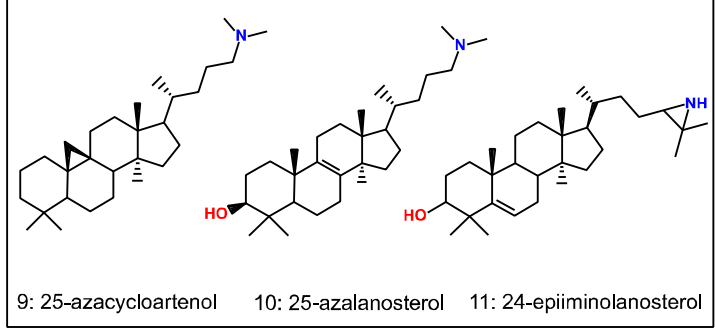

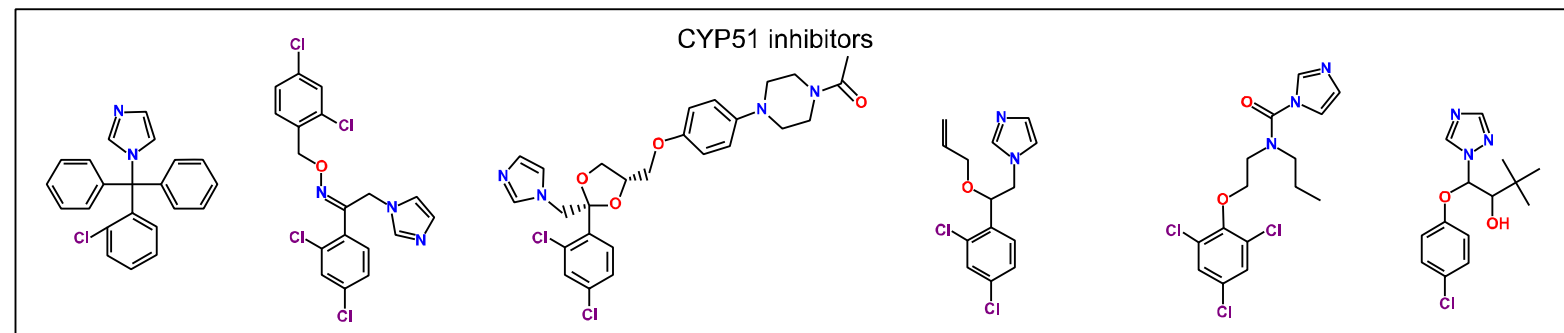

12: Clotrimazole

13: Oxiconazole

14: Ketoconazole

15: Imazalil/enilconazole

16: Prochloraz

17: Triadimenol
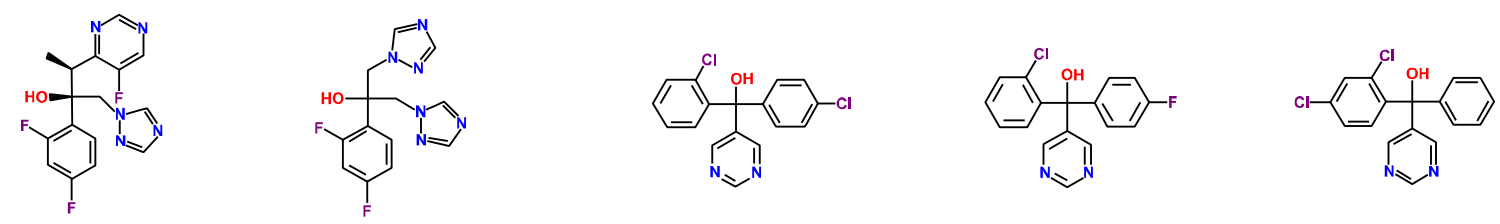

18: Voriconazole

19: Fluconazole

20: Fenarimol

21: Nuarimol

22: Triarimol

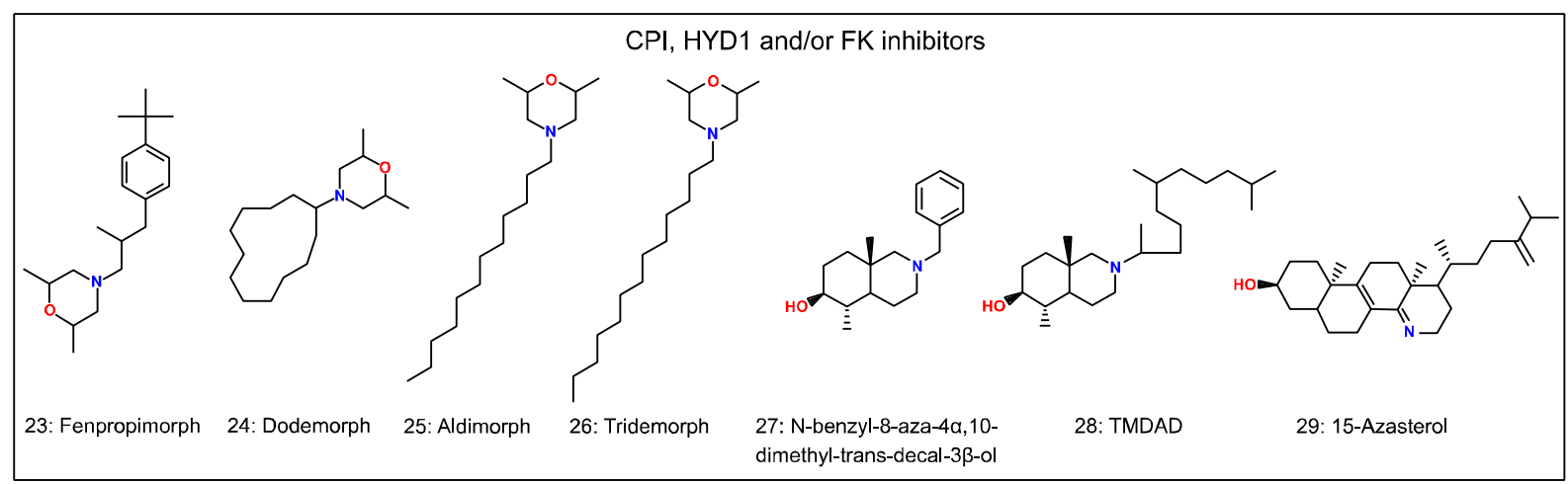

Fig. 3. Structures of sterol biosynthesis inhibitors organized according to their putative targets.

Acknowledgments: K.D.V. is funded by the Special Research Fund Ghent University. 
bioRxiv preprint doi: https://doi.org/10.1101/784272; this version posted September 26, 2019. The copyright holder for this preprint (which was not certified by peer review) is the author/funder, who has granted bioRxiv a license to display the preprint in perpetuity. It is made available under aCC-BY 4.0 International license.

560 Author Contributions: "Conceptualization, K.D.V and S.V..; All authors contributed to the writing and

561 revision of the manuscript

562 Conflicts of Interest: The authors declare no conflict of interest

563 


\section{References}

565 Asami T, Min YK, Nagata N, Yamagishi K, Takatsuto S, Fujioka S, Murofushi N, Yamaguchi I, Yoshida S. 2000.

566 Characterization of brassinazole, a triazole-type brassinosteroid biosynthesis inhibitor. Plant Physiol 123, 93-100.

567 Ator MA, Schmidt SJ, Adams JL, Dolle RE, Kruse LI, Frey CL, Barone JM. 1992. Synthesis, specificity, and

568 antifungal activity of inhibitors of the Candida albicans delta 24-sterol methyltransferase. Journal of medicinal 569 chemistry 35, 100-106.

570 Azpiroz R, Wu Y, LoCascio JC, Feldmann KA. 1998. An Arabidopsis brassinosteroid-dependent mutant is blocked 571 in cell elongation. The Plant cell 10, 219-230.

572 Babiychuk E, Bouvier-Nave P, Compagnon V, Suzuki M, Muranaka T, Van Montagu M, Kushnir S, Schaller H. 573 2008. Allelic mutant series reveal distinct functions for Arabidopsis cycloartenol synthase 1 in cell viability and plastid 574 biogenesis. Proceedings of the National Academy of Sciences of the United States of America 105, 3163-3168.

575 Bach TJ, Lichtenthaler HK. 1982. Mevinolin: a highly specific inhibitor of microsomal 3-hydroxy-3-methylglutaryl576 coenzyme A reductase of radish plants. Zeitschrift fur Naturforschung. Section C, Biosciences 37, 46-50.

577 Bach TJ, Lichtenthaler HK. 1987. Plant-Growth Regulation by Mevinolin and Other Sterol Biosynthesis Inhibitors. 578 Acs Symposium Series 325, 109-139.

579 Baloch RI, Mercer El. 1987. Inhibition of Sterol Delta-8-]Delta-7-Isomerase and Delta-14-Reductase by 580 Fenpropimorph, Tridemorph and Fenpropidin in Cell-Free Enzyme-Systems from Saccharomyces-Cerevisiae. 581 Phytochemistry 26, 663-668.

582 Baloch RI, Mercer El, Wiggins TE, Baldwin BC. 1984. Inhibition of Ergosterol Biosynthesis in Saccharomyces583 Cerevisiae and Ustilago-Maydis by Tridemorph, Fenpropimorph and Fenpropidin. Phytochemistry 23, 2219-2226.

584 Banerjee A, Sharkey TD. 2014. Methylerythritol 4-phosphate (MEP) pathway metabolic regulation. Natural product 585 reports 31, 1043-1055.

586 Baxter A, Fitzgerald BJ, Hutson JL, McCarthy AD, Motteram JM, Ross BC, Sapra M, Snowden MA, Watson

587 NS, Williams RJ, et al. 1992. Squalestatin 1, a potent inhibitor of squalene synthase, which lowers serum cholesterol 588 in vivo. The Journal of biological chemistry 267, 11705-11708.

589 Becher R, Wirsel SG. 2012. Fungal cytochrome P450 sterol 14alpha-demethylase (CYP51) and azole resistance in 590 plant and human pathogens. Applied microbiology and biotechnology 95, 825-840.

591 Behrman EJ, Gopalan V. 2005. Cholesterol and plants. Journal of Chemical Education 82, 1791-1793.

592 Benveniste P. 1986. Sterol Biosynthesis. Annual Review of Plant Physiology and Plant Molecular Biology 37, 275593308.

594 Benveniste P. 2002. Sterol metabolism. The arabidopsis book 1, e0004.

595 Benveniste P. 2004. Biosynthesis and accumulation of sterols. Annual review of plant biology 55, 429-457.

596 Bergstrom JD, Kurtz MM, Rew DJ, Amend AM, Karkas JD, Bostedor RG, Bansal VS, Dufresne C, 597 VanMiddlesworth FL, Hensens OD, et al. 1993. Zaragozic acids: a family of fungal metabolites that are picomolar 598 competitive inhibitors of squalene synthase. Proceedings of the National Academy of Sciences of the United States of 599 America 90, 80-84.

600 Berry AM, Harriott OT, Moreau RA, Osman SF, Benson DR, Jones AD. 1993. Hopanoid lipids compose the 601 Frankia vesicle envelope, presumptive barrier of oxygen diffusion to nitrogenase. Proc Natl Acad Sci U S A 90, 60916026094.

603 Birnbaum JE. 1990. Pharmacology of the allylamines. Journal of the American Academy of Dermatology 23, 782604785. 
605

606

607

608

609

610

611

612

613

614

615

616

617

618

619

620

621

622

623

624

625

626

627

628

629

630

631

632

633

634

635

636

637

638

639

640

641

642

643

644

Bladocha M, Benveniste P. 1983. Manipulation by tridemorph, a systemic fungicide, of the sterol composition of maize leaves and roots. Plant physiology 71, 756-762.

Bode HB, Zeggel B, Silakowski B, Wenzel SC, Reichenbach H, Muller R. 2003. Steroid biosynthesis in prokaryotes: identification of myxobacterial steroids and cloning of the first bacterial 2,3(S)-oxidosqualene cyclase from the myxobacterium Stigmatella aurantiaca. Mol Microbiol 47, 471-481.

Boucher Y, Kamekura M, Doolittle WF. 2004. Origins and evolution of isoprenoid lipid biosynthesis in archaea. Mol Microbiol 52, 515-527.

Bouvier-Nave P, Husselstein T, Benveniste P. 1998. Two families of sterol methyltransferases are involved in the first and the second methylation steps of plant sterol biosynthesis. European journal of biochemistry 256, 88-96.

Bouvier-Nave P, Husselstein T, Desprez T, Benveniste P. 1997. Identification of cDNAs encoding sterol methyltransferases involved in the second methylation step of plant sterol biosynthesis. European journal of biochemistry 246, 518-529.

Buchenauer H, Rohner E. 1981. Effect of Triadimefon and Triadimenol on Growth of Various Plant-Species as Well as on Gibberellin Content and Sterol-Metabolism in Shoots of Barley Seedlings. Pesticide Biochemistry and Physiology 15, 58-70.

Buhaescu I, Izzedine H. 2007. Mevalonate pathway: a review of clinical and therapeutical implications. Clinical biochemistry 40, 575-584.

Burden RS, Clark T, Holloway PJ. 1987. Effects of Sterol Biosynthesis-Inhibiting Fungicides and Plant-Growth Regulators on the Sterol Composition of Barley Plants. Pesticide Biochemistry and Physiology 27, 289-300.

Busquets A, Keim V, Closa M, del Arco A, Boronat A, Arro M, Ferrer A. 2008. Arabidopsis thaliana contains a single gene encoding squalene synthase. Plant molecular biology 67, 25-36.

Cacas JL, Furt F, Le Guedard M, Schmitter JM, Bure C, Gerbeau-Pissot P, Moreau P, Bessoule JJ, SimonPlas F, Mongrand S. 2012. Lipids of plant membrane rafts. Progress in lipid research 51, 272-299.

Cardenas PD, Sonawane PD, Heinig U, Bocobza SE, Burdman S, Aharoni A. 2015. The bitter side of the nightshades: Genomics drives discovery in Solanaceae steroidal alkaloid metabolism. Phytochemistry 113, 24-32.

Carland F, Fujioka S, Nelson T. 2010. The sterol methyltransferases SMT1, SMT2, and SMT3 influence Arabidopsis development through nonbrassinosteroid products. Plant physiology 153, 741-756.

Carland FM, Fujioka S, Takatsuto S, Yoshida S, Nelson T. 2002. The identification of CVP1 reveals a role for sterols in vascular patterning. The Plant cell 14, 2045-2058.

Cattel L, Ceruti M, Viola F, Delprino L, Balliano G, Duriatti A, Bouvier-Nave P. 1986. The squalene-2,3-epoxide cyclase as a model for the development of new drugs. Lipids 21, 31-38.

Catterou M, Dubois F, Schaller H, Aubanelle L, Vilcot B, Sangwan-Norreel BS, Sangwan RS. 2001. Brassinosteroids, microtubules and cell elongation in Arabidopsis thaliana. I. Molecular, cellular and physiological characterization of the Arabidopsis bull mutant, defective in the delta 7-sterol-C5-desaturation step leading to brassinosteroid biosynthesis. Planta 212, 659-672.

Chappell J. 2002. The genetics and molecular genetics of terpene and sterol origami. Current opinion in plant biology 5, 151-157.

Choe S, Dilkes BP, Gregory BD, Ross AS, Yuan H, Noguchi T, Fujioka S, Takatsuto S, Tanaka A, Yoshida S, Tax FE, Feldmann KA. 1999. The Arabidopsis dwarf1 mutant is defective in the conversion of 24methylenecholesterol to campesterol in brassinosteroid biosynthesis. Plant physiology 119, 897-907. 

Feldmann KA. 1999. The Arabidopsis dwf7/ste1 mutant is defective in the delta7 sterol C-5 desaturation step leading to brassinosteroid biosynthesis. The Plant cell 11, 207-221.

648 Choe S, Tanaka A, Noguchi T, Fujioka S, Takatsuto S, Ross AS, Tax FE, Yoshida S, Feldmann KA. 2000. Lesions in the sterol delta reductase gene of Arabidopsis cause dwarfism due to a block in brassinosteroid biosynthesis. The Plant journal : for cell and molecular biology 21, 431-443. Clouse SD. 2000. Plant development: A role for sterols in embryogenesis. Current biology : CB 10, R601-604. Clouse SD. 2002. Arabidopsis mutants reveal multiple roles for sterols in plant development. The Plant cell 14, 19952000.

654 Clouse SD. 2011. Brassinosteroids. The arabidopsis book 9, e0151.

655 Darnet S, Rahier A. 2004. Plant sterol biosynthesis: identification of two distinct families of sterol 4alpha-methyl 656 oxidases. The Biochemical journal 378, 889-898.

657 Davies JT, Delfino SF, Feinberg CE, Johnson MF, Nappi VL, Olinger JT, Schwab AP, Swanson HI. 2016. 658 Current and Emerging Uses of Statins in Clinical Therapeutics: A Review. Lipid insights 9, 13-29.

Dellas N, Noel JP. 2010. Mutation of archaeal isopentenyl phosphate kinase highlights mechanism and guides phosphorylation of additional isoprenoid monophosphates. ACS chemical biology 5, 589-601.

Diener AC, Li H, Zhou W, Whoriskey WJ, Nes WD, Fink GR. 2000. Sterol methyltransferase 1 controls the level of 662 cholesterol in plants. The Plant cell 12, 853-870.

663 Dinan L. 2001. Phytoecdysteroids: biological aspects. Phytochemistry 57, 325-339.

664 Doblas VG, Amorim-Silva V, Pose D, Rosado A, Esteban A, Arro M, Azevedo H, Bombarely A, Borsani O, 665 Valpuesta V, Ferrer A, Tavares RM, Botella MA. 2013. The SUD1 gene encodes a putative E3 ubiquitin ligase and 666 is a positive regulator of 3-hydroxy-3-methylglutaryl coenzyme a reductase activity in Arabidopsis. The Plant cell 25, 667 728-743.

668 Douglas TJ, Paleg LG. 1978. Amo 1618 and Sterol Biosynthesis in Tissues and Subcellular-Fractions of Tobacco 669 Seedlings. Phytochemistry 17, 705-712.

670 Douglas TJ, Paleg LG. 1978. Amo 1618 Effects on Incorporation of Mva-C-14 and Acetate-C-14 into Sterols in 671 Nicotiana and Digitalis Seedlings and Cell-Free Preparations from Nicotiana. Phytochemistry 17, 713-718.

672 Douglas TJ, Paleg LG. 1981. Inhibition of Sterol Biosynthesis and Stem Elongation of Tobacco Seedlings Induced 673 by Some Hypocholesterolemic Agents. Journal of Experimental Botany 32, 59-68.

674 Duriatti A, Bouvier-Nave P, Benveniste P, Schuber F, Delprino L, Balliano G, Cattel L. 1985. In vitro inhibition of 675 animal and higher plants 2,3-oxidosqualene-sterol cyclases by 2-aza-2,3-dihydrosqualene and derivatives, and by 676 other ammonium-containing molecules. Biochemical pharmacology 34, 2765-2777.

677 Edwards PA, Ericsson J. 1999. Sterols and isoprenoids: signaling molecules derived from the cholesterol 678 biosynthetic pathway. Annual review of biochemistry 68, 157-185.

679 Enjuto M, Balcells L, Campos N, Caelles C, Arro M, Boronat A. 1994. Arabidopsis thaliana contains two 680 differentially expressed 3-hydroxy-3-methylglutaryl-CoA reductase genes, which encode microsomal forms of the 681 enzyme. Proc Natl Acad Sci U S A 91, 927-931.

682 Enjuto M, Lumbreras V, Marin C, Boronat A. 1995. Expression of the Arabidopsis HMG2 gene, encoding 3683 hydroxy-3-methylglutaryl coenzyme A reductase, is restricted to meristematic and floral tissues. Plant Cell 7, 517684527. 
Fabris M, Matthijs M, Carbonelle S, Moses T, Pollier J, Dasseville R, Baart GJ, Vyverman W, Goossens A. 2014. Tracking the sterol biosynthesis pathway of the diatom Phaeodactylum tricornutum. The New phytologist 204, 521-535.

Farese RV, Jr., Herz J. 1998. Cholesterol metabolism and embryogenesis. Trends in genetics : TIG 14, 115-120. Fujioka S, Sakurai A. 1997. Brassinosteroids. Natural product reports 14, 1-10.

Fujiyama K, Hino T, Kanadani M, Watanabe B, Jae Lee H, Mizutani M, Nagano S. 2019. Structural insights into a key step of brassinosteroid biosynthesis and its inhibition. Nat Plants 5, 589-594.

Gachotte D, Husselstein T, Bard M, Lacroute F, Benveniste P. 1996. Isolation and characterization of an Arabidopsis thaliana cDNA encoding a delta 7-sterol-C-5-desaturase by functional complementation of a defective yeast mutant. The Plant journal : for cell and molecular biology 9, 391-398.

Galea AM, Brown AJ. 2009. Special relationship between sterols and oxygen: were sterols an adaptation to aerobic life? Free Radic Biol Med 47, 880-889.

Gas-Pascual E, Berna A, Bach TJ, Schaller H. 2014. Plant oxidosqualene metabolism: cycloartenol synthasedependent sterol biosynthesis in Nicotiana benthamiana. PloS one 9, e109156.

Goldstein JL, Brown MS. 1990. Regulation of the mevalonate pathway. Nature 343, 425-430.

Grandmougin-Ferjani A, Schuler-Muller I, Hartmann MA. 1997. Sterol Modulation of the Plasma Membrane $\mathrm{H}_{+}-$ ATPase Activity from Corn Roots Reconstituted into Soybean Lipids. Plant physiology 113, 163-174.

Grunwald C. 1971. Effects of free sterols, steryl ester, and steryl glycoside on membrane permeability. Plant physiology 48, 653-655.

Guo DA, Venkatramesh M, Nes WD. 1995. Developmental regulation of sterol biosynthesis in Zea mays. Lipids $\mathbf{3 0}$, 203-219.

Hartmann MA. 1998. Plant sterols and the membrane environment. Trends in Plant Science 3, 170-175.

Hartmann MA, Benveniste P. 1987. Plant Membrane Sterols - Isolation, Identification, and Biosynthesis. Methods in Enzymology 148: 632-650.

Hartmann MA, Wentzinger L, Hemmerlin A, Bach TJ. 2000. Metabolism of farnesyl diphosphate in tobacco BY-2 cells treated with squalestatin. Biochemical Society transactions 28, 794-796.

He JX, Fujioka S, Li TC, Kang SG, Seto H, Takatsuto S, Yoshida S, Jang JC. 2003. Sterols regulate development and gene expression in Arabidopsis. Plant physiology 131, 1258-1269.

He Z, Wang ZY, Li J, Zhu Q, Lamb C, Ronald P, Chory J. 2000. Perception of brassinosteroids by the extracellular domain of the receptor kinase BRI1. Science (New York, N.Y.) 288, 2360-2363.

Henry LK, Gutensohn M, Thomas ST, Noel JP, Dudareva N. 2015. Orthologs of the archaeal isopentenyl phosphate kinase regulate terpenoid production in plants. Proceedings of the National Academy of Sciences of the United States of America 112, 10050-10055.

Henry LK, Thomas ST, Widhalm JR, Lynch JH, Davis TC, Kessler SA, BohImann J, Noel JP, Dudareva N. 2018. Contribution of isopentenyl phosphate to plant terpenoid metabolism. Nature plants 4, 721-729.

Hodzic A, Rappolt M, Amenitsch H, Laggner P, Pabst G. 2008. Differential modulation of membrane structure and fluctuations by plant sterols and cholesterol. Biophysical journal 94, 3935-3944.

Hoshino T, Kobayashi N, Ishibashi E, Hashimoto S. 1995. Inhibitory activity of 8-azadecalin derivatives towards 2,3-oxidosqualene:lanosterol cyclases from baker's yeast and pig's liver. Bioscience, biotechnology, and biochemistry $59,602-609$.

Istvan ES, Deisenhofer J. 2001. Structural mechanism for statin inhibition of HMG-CoA reductase. Science (New York, N.Y.) 292, 1160-1164. 
Japelt RB, Jakobsen J. 2013. Vitamin D in plants: a review of occurrence, analysis, and biosynthesis. Frontiers in plant science 4, 136.

Kerkenaar A. 1987. Mechanism of action of morpholine fungicides. Modern Selective Fungicides - Properties,

Kerkenaar A, Uchiyama M, Versluis GG. 1981. Specific Effects of Tridemorph on Sterol Biosynthesis in UstilagoMaydis. Pesticide Biochemistry and Physiology 16, 97-104.

Kim YJ, Lee OR, Oh JY, Jang MG, Yang DC. 2014. Functional analysis of 3-hydroxy-3-methylglutaryl coenzyme a reductase encoding genes in triterpene saponin-producing ginseng. Plant physiology 165, 373-387.

Klahre U, Noguchi T, Fujioka S, Takatsuto S, Yokota T, Nomura T, Yoshida S, Chua NH. 1998. The Arabidopsis DIMINUTO/DWARF1 gene encodes a protein involved in steroid synthesis. The Plant cell 10, 1677-1690.

Kolesnikova MD, Xiong Q, Lodeiro S, Hua L, Matsuda SP. 2006. Lanosterol biosynthesis in plants. Archives of biochemistry and biophysics 447, 87-95. Characterization of three novel isoprenyl diphosphate synthases from the terpenoid rich mango fruit. Plant physiology and biochemistry : PPB 71, 121-131.

742 Laloi M, Perret AM, Chatre L, Melser S, Cantrel C, Vaultier MN, Zachowski A, Bathany K, Schmitter JM, Vallet M, Lessire R, Hartmann MA, Moreau P. 2007. Insights into the role of specific lipids in the formation and delivery of lipid microdomains to the plasma membrane of plant cells. Plant physiology 143, 461-472. 2015. Arabidopsis Squalene Epoxidase 3 (SQE3) Complements SQE1 and Is Important for Embryo Development and Bulk Squalene Epoxidase Activity. Molecular plant 8, 1090-1102. Academy of Sciences of the United States of America 100, 6866-6871. cerevisiae. Antimicrob Agents Chemother 47, 3890-3900.

754 Lenton JR. 1987. Mode of action of triazole growth retardants and fungicides-a progress report. New Bull Brit Plant 755 Growth Reg Group 9, 1-12.

756 Lepesheva GI, Waterman MR. 2007. Sterol 14alpha-demethylase cytochrome P450 (CYP51), a P450 in all 757 biological kingdoms. Biochimica et biophysica acta 1770, 467-477.

758 Leroux P, Bach J, Debieu D, Fillinger S, Fritz R, Walker AS. 2008. Mode of action of sterol biosynthesis inhibitors 759 and resistance phenomena in fungi. Modern Fungicides and Antifungal Compounds V.

760 Lindsey K, Pullen ML, Topping JF. 2003. Importance of plant sterols in pattern formation and hormone signalling. 761 Trends in plant science 8, 521-525.

762 Lohr M, Schwender J, Polle JE. 2012. Isoprenoid biosynthesis in eukaryotic phototrophs: a spotlight on algae. Plant 763 Sci 185-186, 9-22.

764 Lombard J, Moreira D. 2011. Origins and early evolution of the mevalonate pathway of isoprenoid biosynthesis in 765 the three domains of life. Mol Biol Evol 28, 87-99.

766 Lurssen K. 1987. Physiological-Effects of Triazole Pgr in Relation to Their Biochemical-Mode of Action. Pesticide 767 Science 21, 310-311. 
Malinsky J, Opekarova M, Grossmann G, Tanner W. 2013. Membrane microdomains, rafts, and detergentresistant membranes in plants and fungi. Annual review of plant biology 64, 501-529.

Mangiarotti A, Genovese DM, Naumann CA, Monti MR, Wilke N. 2019. Hopanoids, like sterols, modulate dynamics, compaction, phase segregation and permeability of membranes. Biochim Biophys Acta Biomembr 1861, 183060.

Mangla AT, Nes WD. 2000. Sterol C-methyl transferase from Prototheca wickerhamii mechanism, sterol specificity and inhibition. Bioorganic \& medicinal chemistry 8, 925-936.

Manzano D, Andrade P, Caudepon D, Altabella T, Arro M, Ferrer A. 2016. Suppressing Farnesyl Diphosphate Synthase Alters Chloroplast Development and Triggers Sterol-Dependent Induction of Jasmonate- and Fe-Related Responses. Plant Physiol 172, 93-117.

Marcireau C, Guilloton M, Karst F. 1990. Invivo Effects of Fenpropimorph on the Yeast Saccharomyces-Cerevisiae and Determination of the Molecular-Basis of the Antifungal Property. Antimicrobial Agents and Chemotherapy 34, 989-993.

Meance J, Duperon P, Duperon R. 1976. Localization of Sterol Compounds inside Mitochondria from Cauliflower Buds. Physiologie Vegetale 14, 745-756.

Men S, Boutte Y, Ikeda Y, Li X, Palme K, Stierhof YD, Hartmann MA, Moritz T, Grebe M. 2008. Sterol-dependent endocytosis mediates post-cytokinetic acquisition of PIN2 auxin efflux carrier polarity. Nature cell biology 10, 237244.

Mendoza-Poudereux I, Kutzner E, Huber C, Segura J, Eisenreich W, Arrillaga I. 2015. Metabolic cross-talk between pathways of terpenoid backbone biosynthesis in spike lavender. Plant Physiol Biochem 95, 113-120.

Mercer El, Khalil IA, Wang ZX. 1989. Effect of some sterol-biosynthesis-inhibiting fungicides on the biosynthesis of polyisoprenoid compounds in barley seedings. Steroids 53, 393-412.

Milner SE, Brunton NP, Jones PW, O'Brien NM, Collins SG, Maguire AR. 2011. Bioactivities of glycoalkaloids and their aglycones from Solanum species. Journal of agricultural and food chemistry 59, 3454-3484.

Mongrand S, Morel J, Laroche J, Claverol S, Carde JP, Hartmann MA, Bonneu M, Simon-Plas F, Lessire R, Bessoule JJ. 2004. Lipid rafts in higher plant cells: purification and characterization of Triton X-100-insoluble microdomains from tobacco plasma membrane. The Journal of biological chemistry 279, 36277-36286.

Morikawa T, Mizutani M, Aoki N, Watanabe B, Saga H, Saito S, Oikawa A, Suzuki H, Sakurai N, Shibata D, Wadano A, Sakata K, Ohta D. 2006. Cytochrome P450 CYP710A encodes the sterol C-22 desaturase in Arabidopsis and tomato. The Plant cell 18, 1008-1022.

Mouritsen OG. 2005. Cholesterol on the scene. Life-as a matter of fat: the emerging science of lipidomics, 149-157 Murray M. 1999. Mechanisms and significance of inhibitory drug interactions involving cytochrome P450 enzymes (review). Int J Mol Med 3, 227-238.

Neelakandan AK, Song Z, Wang J, Richards MH, Wu X, Valliyodan B, Nguyen HT, Nes WD. 2009. Cloning, functional expression and phylogenetic analysis of plant sterol 24C-methyltransferases involved in sitosterol biosynthesis. Phytochemistry 70, 1982-1998.

Nes WD. 2000. Sterol methyl transferase: enzymology and inhibition. Biochimica et biophysica acta 1529, 63-88 Nes WD. 2011. Biosynthesis of cholesterol and other sterols. Chemical reviews 111, 6423-6451.

Nowosielski M, Hoffmann M, Wyrwicz LS, Stepniak P, Plewczynski DM, Lazniewski M, Ginalski K, Rychlewski L. 2011. Detailed mechanism of squalene epoxidase inhibition by terbinafine. J Chem Inf Model 51, 455-462.

Oh K, Matsumoto T, Yamagami A, Hoshi T, Nakano T, Yoshizawa Y. 2015. Fenarimol, a Pyrimidine-Type Fungicide, Inhibits Brassinosteroid Biosynthesis. International journal of molecular sciences 16, 17273-17288. 
Ohyama K, Suzuki M, Kikuchi J, Saito K, Muranaka T. 2009. Dual biosynthetic pathways to phytosterol via cycloartenol and lanosterol in Arabidopsis. Proceedings of the National Academy of Sciences of the United States of

812 America 106, 725-730.

813 Pan J, Fujioka S, Peng J, Chen J, Li G, Chen R. 2009. The E3 ubiquitin ligase SCFTIR1/AFB and membrane 814 sterols play key roles in auxin regulation of endocytosis, recycling, and plasma membrane accumulation of the auxin 815 efflux transporter PIN2 in Arabidopsis thaliana. The Plant cell 21, 568-580.

816 Piironen V, Lindsay DG, Miettinen TA, Toivo J, Lampi AM. 2000. Plant sterols: biosynthesis, biological function 817 and their importance to human nutrition. Journal of the Science of Food and Agriculture 80, 939-966.

818 Pollier J, Vancaester E, Kuzhiumparambil U, Vickers CE, Vandepoele K, Goossens A, Fabris M. 2019. A 819 widespread alternative squalene epoxidase participates in eukaryote steroid biosynthesis. Nature microbiology 4: $820 \quad 226-233$.

821 Pose D, Castanedo I, Borsani O, Nieto B, Rosado A, Taconnat L, Ferrer A, Dolan L, Valpuesta V, Botella MA. 822 2009. Identification of the Arabidopsis dry2/sqe1-5 mutant reveals a central role for sterols in drought tolerance and 823 regulation of reactive oxygen species. The Plant journal : for cell and molecular biology 59, 63-76. Rahier A, Genot JC, Schuber F, Benveniste P, Narula AS. 1984. Inhibition of S-adenosyl-L-methionine sterol-C24-methyltransferase by analogues of a carbocationic ion high-energy intermediate. Structure activity relationships for C-25 heteroatoms ( $\mathrm{N}, \mathrm{As}, \mathrm{S}$ ) substituted triterpenoid derivatives. The Journal of biological chemistry 259, 1521515223.

Rahier A, Narula AS, Benveniste P, Schmitt P. 1980. 25-Azacycloartanol, a potent inhibitor of S-adenosyl-Lmethionine-sterol-C-24 and C-28 methyltransferases in higher plant cells. Biochemical and biophysical research communications 92, 20-25.

Rahier A, Schmitt P, Huss B, Benveniste P, Pommer EH. 1986. Chemical-Structure Activity Relationships of the Inhibition of Sterol Biosynthesis by N-Substituted Morpholines in Higher-Plants. Pesticide Biochemistry and Physiology 25, 112-124.

Rahier A, Taton M. 1986. The 14 alpha-demethylation of obtusifoliol by a cytochrome P-450 monooxygenase from higher plants' microsomes. Biochemical and biophysical research communications 140, 1064-1072. Isomerase and of Cycloeucalenol Obtusifoliol Isomerase by N-Benzyl-8-Aza-4-Alpha,10-Dimethyl-Trans-Decal-3Beta-OI, an Analog of a Carbocationic High-Energy Intermediate. Phytochemistry 24, 1223-1232. epoxidase 1 is essential for root and seed development. The Journal of biological chemistry 282, 17002-17013. Beta-Trimethyl-Trans-Decal-3-Beta-OI(Tmd). Synthetic Communications 20, 2723-2731.

846 Biochimica et biophysica acta 176, 892-894.

847 Rivas-Marin E, Stettner S, Gottshall EY, Santana-Molina C, Helling M, Basile F, Ward NL, Devos DP. 2019.

848 Essentiality of sterol synthesis genes in the planctomycete bacterium Gemmata obscuriglobus. Nat Commun 10, 8492916.

850 Rogerson TD, Wilkinson CF, Hetarski K. 1977. Steric factors in the inhibitory interaction of imidazoles with 851 microsomal enzymes. Biochemical pharmacology 26, 1039-1042. 
853 Fujioka S, Poppenberger B. 2013. Genetic variation in plant CYP51s confers resistance against voriconazole, a novel inhibitor of brassinosteroid-dependent sterol biosynthesis. PloS one 8, e53650.

855 Ruhl KK, Anzalone L, Arguropoulos ED, Gayen AK, Spencer TA. 1989. Azadecalin Analogs of 4,4,10beta-

856 Trimethyl-Trans-Decal-3beta-Ol - Synthesis and Assay as Inhibitors of Oxidosqualene Cyclase. Bioorganic Chemistry

857 17, 108-120.

858 Ryder NS. 1991. Squalene epoxidase as a target for the allylamines. Biochemical Society transactions 19, 774-777.

859 Saenz JP, Grosser D, Bradley AS, Lagny TJ, Lavrynenko O, Broda M, Simons K. 2015. Hopanoids as functional analogues of cholesterol in bacterial membranes. Proc Natl Acad Sci U S A 112, 11971-11976. Mizutani M. 2006. A plant growth retardant, uniconazole, is a potent inhibitor of ABA catabolism in Arabidopsis. Biosci Biotechnol Biochem 70, 1731-1739.

Sawai S, Akashi T, Sakurai N, Suzuki H, Shibata D, Ayabe S, Aoki T. 2006. Plant lanosterol synthase: divergence of the sterol and triterpene biosynthetic pathways in eukaryotes. Plant \& cell physiology 47, 673-677. growth in Arabidopsis is controlled by STEROL METHYLTRANSFERASE 2;1. The Plant journal : for cell and molecular biology 25, 605-615.

Schaller H. 2003. The role of sterols in plant growth and development. Progress in lipid research 42, 163-175.

Schaller H. 2004. New aspects of sterol biosynthesis in growth and development of higher plants. Plant physiology and biochemistry : PPB 42, 465-476.

Schaller H, Bouvier-Nave P, Benveniste P. 1998. Overexpression of an Arabidopsis cDNA encoding a sterolC24(1)-methyltransferase in tobacco modifies the ratio of 24-methyl cholesterol to sitosterol and is associated with growth reduction. Plant physiology 118, 461-469. fungicides. Modern selective Fungicides - Properties, Applications, Mechanisms of Action, 173-204.

Schmitt P, Benveniste P. 1979. Effect of Fenarimol on Sterol Biosynthesis in Suspension Cultures of Bramble Cells. Phytochemistry 18, 1659-1665.

Schmitt P, Narula AS, Benveniste P, Rahier A. 1981. Manipulation by 25-Azacycloartanol of the Relative Percentage of C10, C9 and C8 Side-Chain Sterols in Suspension-Cultures of Bramble Cells. Phytochemistry 20, 197-

Schmitt P, Scheid F, Benveniste P. 1980. Accumulation of Delta-8,14-Sterols in Suspension-Cultures of Bramble Cells Cultured with an Azasterol Anti-Mycotic Agent (A25822b). Phytochemistry 19, 525-530.

884 Schrick K, Mayer U, Horrichs A, Kuhnt C, Bellini C, Dangl J, Schmidt J, Jurgens G. 2000. FACKEL is a sterol C14 reductase required for organized cell division and expansion in Arabidopsis embryogenesis. Genes \& development 14, 1471-1484.

887 Schrick K, Mayer U, Martin G, Bellini C, Kuhnt C, Schmidt J, Jurgens G. 2002. Interactions between sterol 888 biosynthesis genes in embryonic development of Arabidopsis. The Plant journal: for cell and molecular biology 31, $88961-73$.

890 Schuler I, Duportail G, Glasser N, Benveniste P, Hartmann MA. 1990. Soybean phosphatidylcholine vesicles 891 containing plant sterols: a fluorescence anisotropy study. Biochimica et biophysica acta 1028, 82-88. 
Schuler I, Milon A, Nakatani Y, Ourisson G, Albrecht AM, Benveniste P, Hartman MA. 1991. Differential effects of plant sterols on water permeability and on acyl chain ordering of soybean phosphatidylcholine bilayers. Proceedings of the National Academy of Sciences of the United States of America 88, 6926-6930.

Shi J, Gonzales RA, Bhattacharyya MK. 1996. Identification and characterization of an S-adenosyl-L-methionine: delta 24-sterol-C-methyltransferase cDNA from soybean. The Journal of biological chemistry 271, 9384-9389. Shive JB, Sisler HD. 1976. Effects of Ancymidol (a Growth Retardant) and Triarimol (a Fungicide) on the Growth, Sterols, and Gibberellins of Phaseolus vulgaris (L.). Plant physiology 57, 640-644.

Simon-Plas F, Perraki A, Bayer E, Gerbeau-Pissot P, Mongrand S. 2011. An update on plant membrane rafts. Current opinion in plant biology 14, 642-649.

Simons K, van Meer G. 1988. Lipid sorting in epithelial cells. Biochemistry 27, 6197-6202.

Sonawane PD, Pollier J, Panda S, Szymanski J, Massalha H, Yona M, Unger T, Malitsky S, Arendt P, Pauwels L, Almekias-SiegI E, Rogachev I, Meir S, Cardenas PD, Masri A, Petrikov M, Schaller H, Schaffer AA, Kamble A, Giri AP, Goossens A, Aharoni A. 2016. Plant cholesterol biosynthetic pathway overlaps with phytosterol metabolism. Nature plants 3, 16205.

Soto G, Stritzler M, Lisi C, Alleva K, Pagano ME, Ardila F, Mozzicafreddo M, Cuccioloni M, Angeletti M, Ayub ND. 2011. Acetoacetyl-CoA thiolase regulates the mevalonate pathway during abiotic stress adaptation. Journal of experimental botany 62, 5699-5711.

Souter M, Topping J, Pullen M, Friml J, Palme K, Hackett R, Grierson D, Lindsey K. 2002. hydra Mutants of Arabidopsis are defective in sterol profiles and auxin and ethylene signaling. The Plant cell 14, 1017-1031.

Souter MA, Pullen ML, Topping JF, Zhang X, Lindsey K. 2004. Rescue of defective auxin-mediated gene expression and root meristem function by inhibition of ethylene signalling in sterol biosynthesis mutants of Arabidopsis. Planta 219, 773-783.

Suzuki M, Kamide Y, Nagata N, Seki H, Ohyama K, Kato H, Masuda K, Sato S, Kato T, Tabata S, Yoshida S, Muranaka T. 2004. Loss of function of 3-hydroxy-3-methylglutaryl coenzyme A reductase 1 (HMG1) in Arabidopsis leads to dwarfing, early senescence and male sterility, and reduced sterol levels. The Plant journal : for cell and molecular biology $37,750-761$.

Suzuki M, Xiang T, Ohyama K, Seki H, Saito K, Muranaka T, Hayashi H, Katsube Y, Kushiro T, Shibuya M, Ebizuka Y. 2006. Lanosterol synthase in dicotyledonous plants. Plant \& cell physiology 47, 565-571.

Tal B, Nes WD. 1987. Regulation of sterol biosynthesis: importance of the C-24 alkyl group to growth of sunflower suspension cultures. Plant Physiol. (Suppl.) 83.

Tansey TR, Shechter I. 2001. Squalene synthase: structure and regulation. Progress in nucleic acid research and molecular biology 65, 157-195.

Taton M, Benveniste P, Rahier A. 1987. Comparative-Study of the Inhibition of Sterol Biosynthesis in RubusFruticosus Suspension-Cultures and Zea-Mays Seedlings by N-(1,5,9-Trimethyldecyl)-4-Alpha,10-Dimethyl-8-AzaTrans-Decal-3-Beta-Ol and Derivatives. Phytochemistry 26, 385-392.

Taton M, Benveniste P, Rahier A. 1987. Mechanism of Inhibition of Sterol Biosynthesis Enzymes by N-Substituted Morpholines. Pesticide Science 21, 269-280.

Taton M, Benveniste P, Rahier A. 1989. Microsomal Delta-8,14-Sterol Delta-14-Reductase in Higher-Plants Characterization and Inhibition by Analogs of a Presumptive Carbocationic Intermediate of the Reduction Reaction. European Journal of Biochemistry 185, 605-614.

Thimmappa R, Geisler K, Louveau T, O'Maille P, Osbourn A. 2014. Triterpene biosynthesis in plants. Annual review of plant biology $65,225-257$. 

Nagashima A, Geisler M, Sakai T, Friml J, Peer WA, Murphy AS. 2009. ABCB19/PGP19 stabilises PIN1 in membrane microdomains in Arabidopsis. The Plant journal: for cell and molecular biology 57, 27-44.

937 Topping JF, May VJ, Muskett PR, Lindsey K. 1997. Mutations in the HYDRA1 gene of Arabidopsis perturb cell shape and disrupt embryonic and seedling morphogenesis. Development (Cambridge, England) 124, 4415-4424.

939 Valitova YN, Kotlova ER, Novikov AV, Shavarda AL, Artemenko KA, Zubarev RA, Minibayeva FV. 2010.

940 Binding of sterols affects membrane functioning and sphingolipid composition in wheat roots. Biochemistry.

941 Biokhimiia 75, 554-561.

942 Vanden Bossche H, Marichal P, Gorrens J, Bellens D, Verhoeven H, Coene MC, Lauwers W, Janssen PAJ.

943 1987. Interaction of azole derivatives with cytochrome P-450 isozymes in yeast, fungi, plants and mammalian cells.

944 Pesticide Science 21, 289-306.

945 Vriet C, Russinova E, Reuzeau C. 2013. From squalene to brassinolide: the steroid metabolic and signaling 946 pathways across the plant kingdom. Molecular plant 6, 1738-1757.

947 Warrilow AG, Parker JE, Kelly DE, Kelly SL. 2013. Azole affinity of sterol 14alpha-demethylase (CYP51) enzymes from Candida albicans and Homo sapiens. Antimicrobial agents and chemotherapy 57, 1352-1360.

949 Wentzinger LF, Bach TJ, Hartmann MA. 2002. Inhibition of squalene synthase and squalene epoxidase in tobacco cells triggers an up-regulation of 3-hydroxy-3-methylglutaryl coenzyme A reductase. Plant Physiology 130, 334-346. positioning in Arabidopsis require STEROL METHYLTRANSFERASE1 function. The Plant cell 15, 612-625.

953 Xu J, Wang XY, Guo WZ. 2015. The cytochrome P450 superfamily: Key players in plant development and defense. 954 Journal of Integrative Agriculture 14, 1673-1686.

955 Yang H, Richter GL, Wang X, Mlodzinska E, Carraro N, Ma G, Jenness M, Chao DY, Peer WA, Murphy AS. 956 2013. Sterols and sphingolipids differentially function in trafficking of the Arabidopsis ABCB19 auxin transporter. The

957 Plant journal : for cell and molecular biology 74, 37-47.

958 Yates PJ, Haughan PA, Lenton JR, Goad LJ. 1991. Effects of Terbinafine on Growth, Squalene, and Steryl Ester 959 Content of a Celery Cell-Suspension Culture. Pesticide Biochemistry and Physiology 40, 221-226.

960 Yates PJ, Haughan PA, Lenton JR, Goad LJ. 1992. 4 Delta-5,7-Sterols from Terbinafine Treated Celery Cell961 Suspension Cultures. Phytochemistry 31, 3051-3058.

962 Yoshida S, Uemura M. 1986. Lipid Composition of Plasma Membranes and Tonoplasts Isolated from Etiolated 963 Seedlings of Mung Bean (Vigna radiata L.). Plant physiology 82, 807-812.

964 Zhao L, Chang WC, Xiao Y, Liu HW, Liu P. 2013. Methylerythritol phosphate pathway of isoprenoid biosynthesis. 965 Annual review of biochemistry 82, 497-530. 